\title{
PREDICTION OF DEFAULT OF SMALL COMPANIES IN THE SLOVAK REPUBLIC
}

\author{
Lucia Svabova, ${ }^{1}$ Marek Durica, ${ }^{2}$ Ivana Podhorska ${ }^{3}$ \\ ${ }^{1,2,3}$ Department of Economics, Faculty of Operation and Economics of Transport and Communications, \\ University of Zilina, Zilina, Slovakia, \\ ${ }^{1} l u c i a . s v a b o v a @ f p e d a s . u n i z a . s k$ \\ ${ }^{2}$ marek.durica@fpedas.uniza.sk \\ ${ }^{3}$ ivana.podhorska@fpedas.uniza.sk
}

\begin{abstract}
From the time of Altman and the first bankruptcy prediction models, the prediction of default of companies is in the centre of interest of many economists and scientists all over the world. For companies, early detection of the possible threat of imminent financial difficulties or even bankruptcy is a very important part of financial analysis. Over the last few years, many predictive models have been created in the world. However, it has been shown that these models are not very well transferable to the conditions of the economy of another country and their prediction or rating power in another country is lower. Therefore, it is best to create a specific predictive model in the country that takes into account the situation of companies on the basis of real data on their financial situation. This paper is focused on creating a model of failure prediction of small companies in Slovakia using a well-known and widely used method of multivariate discriminant analysis. Discriminant analysis is one of the oldest multivariate statistical methods and sometimes it is difficult to fulfil certain assumptions for data. However, its results are easily interpretable and can be used to classify a company to the group of companies with risk of financial difficulties or, on the contrary, between well-prosperous companies. Prediction model is created based on real data on Slovak enterprises and has a strong classification ability in the specific conditions of the Slovak Republic.
\end{abstract}

Keywords: prediction of default; bankruptcy prediction models; financial distress; multivariate discriminant analysis

JEL Classification: C38, G33

\section{Introduction}

The prediction of a company's bankruptcy is a matter of interest for many researchers and economists since the early 20th century (Kovacova, Kliestik, 2017). Since then, hundreds of bankruptcy prediction models have been created around the world. Some of them are known worldwide, others only at a national level. As a first study on this issue can be considered the work of P. J. Fitzpatrick from 1932. The study focused on the main differences between successful and unsuccessful companies. The basis for predicting bankruptcy was the analysis of the financial ratios. Further research in the 1960s focused on a univariate analysis (Zvarikova et al., 2017). Beaver, who used univariate discriminant analysis for the first time in 1966, also formed the basis for prediction models in this field. Based on Beaver's recommendation, in 1968 Altman used multidimensional discriminant analysis to develop the prediction model. Using a sample of 33 prosperous and 33 failed companies, he identified five variables that were the most important in predicting bankruptcy (Kocisova et al., 2015).

Since the 1990s, neural networks have been used to predict company's failure (Kral, Bartosova, 2016). Unlike traditional statistical methods, neural networks do not require such restrictive assumptions as linearity, independence, and normal distribution of variables. Neural networks were first used to predict bankruptcy by Odom and. Sharda (Zhang et al., 1999). 
In Slovakia, the first ex-ante analysis was Chrastinová Ch-index, published in 1998. The model was designed for Slovak agricultural companies and is based on discriminant analysis. This specifically oriented model is used not only in Slovakia, but also in the Czech Republic. The second Slovak model, the G-index, the author of which is Gurčík, as well as the CH-index, uses discriminant analysis and also focuses on the agricultural area. Many scientists share the view that it is not appropriate to use foreign models in domestic conditions uncritically, because they were created under different conditions (Kovacova et al., 2017). Therefore, for the prediction of prosperity of Slovak companies, it would be appropriate to use only models that have been constructed in Slovak conditions. This is why, this research is focused on creating a specific model for companies in the Slovak Republic, selecting small companies (up to 50 employees), which are the largest group of companies in Slovakia. The research goal is to create a model for the inclusion of a small company either into a group of prosperous companies or into a group of companies with threatening bankruptcy, where the financial ratios of the companies are used to model this discriminatory function. The prediction model is based on a linear, multivariate discriminant analysis, using the financial ratios of real companies operating in Slovakia in 2015 as explanatory variables. As these indicators indicate the functioning of the company and also its future development, the inclusion of a company into one of the groups of prosperous or non-prosperous ones can be predicted based on the values of these financial ratios. The generated model is a linear combination of 7 financial ratios, from originally used 37 . This prediction model can be used for early identification of financial threats for small companies in Slovakia, one year in advance. Created discriminant model has very good classification ability, especially with regard to the correct classification of non-prosperous companies (93\%). In predicting the financial difficulties of a company, the proper inclusion of the company, which is really in financial troubles, precisely into this category is important; this research is focused on the creation of a discriminant model mainly on this classifying ability of the model.

\section{Literature Review}

Considering the large number of existing models, finding a suitable model for prediction is a role for economists and analysts worldwide (Kovacova, Kliestik, 2017). In order to find the optimal model of bankruptcy prediction, several evaluations and comparisons of existing models were carried out by several authors. Comparison of two mathematical - statistical methods of logit and probit was dealt with by Kovacova and Kliestik (2017). The survey was conducted on the data set of Slovak companies for 2015. The study concluded that the model based on logit function slightly exceeds the precision of the probit model. Finding the most suitable prediction model for transition economies has been dealt by Zvarikova et al. (2017). They compared 42 models constructed in seven selected transition economies to determine which variables in the models are relevant for prediction of bankruptcy. The result of the comparative study was the identification of 20 variables, in which the authors suggest the best prediction accuracy in case of a transition economy and should therefore be used to create new models.

In addition to comparing the existing models, there are nowadays new models created around the world. In 2007, Sandin and Porporato developed a model for the emerging companies in Argentina (Sandin, Porporato, 2017). Boritz et al. (2007) recalculated the coefficients of Altman model using the data of Canadian companies. Similarly, Wang and Campbell (2010) recalculated the coefficients of Altman model for companies in China. Christidis and Gregory (2010) have developed a prediction model for the United Kingdom. The authors point to the importance of taking into account of macroeconomic factors. A model based on multivariate discriminant analysis was presented by Altman et al. (2014). For Iranian companies, Khademolqorani et al. (2015) developed a hybrid model based on a combination of statistical methods and machine learning methods. Singh and Mishra (2016) have developed a prediction model for the Indian manufacturing companies. Alaminos et al. (2016) created a global prediction model based on logistic regression.

Alaka et al. (2016) pointed to different criteria that the scientists used to develop their prediction models. Based on these criteria, they compared the utility of popular bankruptcy prediction tools such as multivariate discriminant analysis, logistic regression, neural networks, genetic algorithms, and more. The authors have concluded that there is no single tool that is predominantly better than any 
other tool with respect to the identified criteria. However, it is clear that each instrument has its strengths and weaknesses in certain situations.

\section{Methodology}

For the purpose of the creation of a prediction model, the method of multidimensional discriminant analysis was used to develop a model of predicting the financial difficulties of Slovak small companies. Discriminant analysis aims to identify the ability of the included quantitative variables to distinguish the data into one of the already existing group of statistical units (Kral et al., 2009). A prediction function of discriminant analysis is to create a classification rule to include unclassified units into one of the groups. The advantage of discriminant analysis is a simple application and interpretation. As disadvantage may prove the necessity of fulfilling a number of assumptions that are imposed on the data. Discriminators, used as explanatory variables to predict the financial difficulties of the companies, must be independent of each other. They must also have a multi-dimensional normal distribution. Meeting this assumption of multidimensional normality will allow to test the statistical significance of the obtained model and to characterize its prediction ability, based on the incorrect classification of the objects into one of the groups. Another assumption of discriminant analysis is that covariance matrices within each group of companies in financial distress and healthy companies must be similar; hence, covariance between input variables should have a comparable size. Moreover, it is advisable to verify the equality of means of explanatory variables among the groups of companies. This verification is used for the initial identification of suitable predictors of financial difficulties of companies. If the mean values of some financial ratio are not significantly different among the groups of prosperous and non-prosperous companies, this financial ratio is probably not an appropriate predictor for identifying the inclusion of a company into one of the groups. Equality of means is tested using two-sample analysis of variance. The advantage of using analysis of variance is that it is sufficiently resistant to not achieving the assumption of multidimensional normality of the predictors used (Hebak et al., 2007).

By using the method of multidimensional discriminant analysis, a classification rule will be derived, that is, with a high probability, that will be able to classify the company into a group of prosperous companies or companies in financial difficulties. Creating a discriminant rule will also get a set of financial ratios that can indicate the company's financial difficulties for at least a year in advance.

To create a model for prediction of bankruptcy of small companies in the Slovak Republic, real data from the financial statements of the Slovak companies was used. The data come from a database Amadeus - a database of comparable financial information for public and private companies across Europe. Data was used from the profit and loss statement, company balance sheet data, as well as the calculated financial ratios provided by Amadeus. The values of the financial ratios are from the year 2015, predicting the possible existence of financial difficulties in the year 2016. Overall, a set of 88 252 small companies was used. The criterion for the inclusion of the company to the group of small ones was in the Amadeus database, that is, primarily the number of employees. A company having up to 50 employees was considered as a small company. Out of a total of 88,252 enterprises, almost $75 \%$ had no financial difficulties in 2016 and the remaining approximately $25 \%$ of companies showed financial distress on the basis of the criteria defined below. The absolute and relative numbers of companies used are given in the following table (Table 1).

Table 1. Frequencies of small companies in financial distress (1) and prosperous small companies (0) (Source: author's compilation)

\begin{tabular}{|c|c|c|c|c|}
\hline \multicolumn{5}{|c|}{ Y } \\
\hline Financial distress & Frequency & Percent & Valid Percent & Cumulative Percent \\
\hline 0 & 66070 & 74.9 & 74.9 & 74.9 \\
\hline $\mathbf{1}$ & 22182 & 25.1 & 25.1 & 100.0 \\
\hline Total & 88252 & 100.0 & 100.0 & \\
\hline
\end{tabular}


The criteria - according to which every company was included either into a group of financially healthy or the group of threatened companies, on the basis of its actual results from the financial statements - are given below. A company was considered as non-prosperous if it met the following three conditions:

- value of current ratio is smaller than 1

- ratio profit / loss is smaller or equal to zero

- solvency ratio (liability based) is smaller than 0.04 (this value is valid for year 2016)

Regarding the financial ratios used, a total of 37 financial ratios, that are usually the most frequently used ratios when creating prediction models, were available. Among these ratios, 13 rations were discarded in the initial data mining phase, mainly due to the high percentage of missing data. The remaining 24 ratios were used as input explanatory variables in the multivariate discriminant analysis. The following table (Table 2) shows all the variables and methods of calculation.

Table 2. Financial ratios used as predictors (Source: author's compilation)

\begin{tabular}{|c|c|c|c|}
\hline $\begin{array}{c}\text { Ratio } \\
\text { name }\end{array}$ & Method for calculation & $\begin{array}{c}\text { Ratio } \\
\text { name }\end{array}$ & Method for calculation \\
\hline X1 & Sales / Total assets & X20 & Net income / Sales \\
\hline X2 & Current assets / Current liabilities & X21 & Non-current liabilities / Total Assets \\
\hline X3 & Gross profit / Total assets & X22 & Cash \& cash equivalents / Current liabilities \\
\hline X4 & Net income / Shareholders equity & X23 & Cash flow / Current liabilities \\
\hline X5 & EBITDA / sales & X24 & Working capital/ Sales \\
\hline X6 & (Non-current + current liabilities) / EBITDA & X25 & Current ratio \\
\hline X7 & Net income/ Total assets & X26 & Return on assets \\
\hline X8 & Working capital / Total assets & X27 & Return on equity \\
\hline X9 & Operating profit / Total assets & X28 & Shareholder liquidity ratio \\
\hline X10 & (Non-current + current liabilities) / total assets & X29 & Solvency ratio (liability based) \\
\hline X11 & Current assets / Total assets & X30 & Cash flow / Operating revenue \\
\hline X12 & Cash \& cash equivalents / Total assets & X31 & Net assets turnover \\
\hline X13 & Cash flow / Total assets & X32 & Interest paid \\
\hline X14 & Cash flow / (Non-current + current liabilities) & X33 & Profit margin \\
\hline X15 & Current liabilities / Total assets & X34 & Net current assets \\
\hline X16 & Current assets / Sales & X35 & Working capital \\
\hline X17 & Operating profit / interest paid & X36 & X37 \\
\hline X18 & Stock / Sales & & \\
\hline X19 & Cash flow / Sales &
\end{tabular}

In order to be able to evaluate the classification ability of the created discriminant model, the set of companies was randomly divided into a training sample and test sample at a rate of 80:20. Then a discriminant model was created on a training sample of 70,738 small companies. Since the discriminant ability of a model certified on a training sample is slightly overvalued, the other 17,514 companies were used to evaluate the percentage of the correct company ranking into one of the groups.

\section{Results}

The first step in the analysis and in the process of creation of prediction model was the selection of suitable predictors of the financial difficulties of small companies in Slovakia. These predictors serve as explanatory variables in the created discriminatory model. Among these, financial ratios was chosen as the appropriate predictors for those variables that differ in their mean value among groups of prosperous companies and healthy companies. The mean values of these two groups of small companies were compared for each financial ratio by a statistical test of equality of means, or analogously by analysis of variance. The results of this testing are given in Table 3 . 
All the ratios, whose values are significantly different in the group of companies in financial problems and in the group of healthy ones, can be considered as suitable predictors in the model of company prosperity.

In this way, using the significance level of 0.05 , all the ratios except the X16, X18, X20 and X24 can be selected as the explanatory variables in the predictive model. As can be seen in Table 3, for these four ratios, the hypothesis of equality of means for a given financial ratio within two groups of companies cannot be rejected. All other ratios can be used as appropriate explanatory variables for creating a model of predicting the financial difficulties of small companies in Slovakia.

Table 3. Tests of Equality of Group Means (Source: author's compilation)

\begin{tabular}{|c|c|c|c|c|c|c|c|}
\hline Variable & Wilks' Lambda & F & Sig. & Variable & Wilks' Lambda & F & Sig. \\
\hline X01 & 1.000 & 15,083 & 0.000 & X20 & 1.000 & 0,039 & 0.843 \\
\hline X02 & 0.991 & 402,018 & 0.000 & X21 & 0.998 & 100,057 & 0.000 \\
\hline X04 & 0.982 & 808,737 & 0.000 & X22 & 0.992 & 343,190 & 0.000 \\
\hline X07 & 0.976 & 1112,340 & 0.000 & X24 & 1.0007 & 0,055 & 0.815 \\
\hline X08 & 1.000 & 7,791 & 0.005 & X25 & 0.991 & 402,020 & 0.000 \\
\hline X09 & 0.980 & 903,152 & 0.000 & X26 & 0.991 & 408,040 & 0.000 \\
\hline X10 & 0.946 & 2569,830 & 0.000 & X27 & 0.978 & 1010,727 & 0.000 \\
\hline X11 & 0.995 & 233,660 & 0.000 & X28 & 0.991 & 427,088 & 0.000 \\
\hline X12 & 0.990 & 454,965 & 0.000 & X30 & 0.997 & 148,839 & 0.000 \\
\hline X15 & 0.952 & 2251,264 & 0.000 & X35 & 0.985 & 700,564 & 0.000 \\
\hline X16 & 1.000 & 0,059 & 0.808 & X36 & 0.990 & 431,541 & 0.000 \\
\hline X18 & 1.000 & 0,053 & 0.817 & X37 & 0.999 & 27,679 & 0.000 \\
\hline
\end{tabular}

The model of predicting the financial distress of small companies was created using a stepwise discriminant analysis. Before the resulting model itself, the validity of the assumptions, required by the discriminant analysis, was tested. Equality of the covariance matrices for the sets of prosperous and non-prosperous companies is verified using the Box Test. Covariance matrix of the two groups should be identical. Test results are presented in Table 4 .

Table 4. Box Tests of Equality of Covariance matrices (Source: author's compilation)

\begin{tabular}{|c|c|}
\hline \multicolumn{2}{|c|}{ Test Results } \\
\hline Box's M & 53913,450 \\
\hline Approx. & 1196,620 \\
\hline df1 & 45 \\
\hline df2 & $\begin{array}{c}65788564,93 \\
0\end{array}$ \\
\hline Sig. & .000 \\
\hline
\end{tabular}

According to the p-value of the Box test shown in Table 4 above, the hypothesis on the equality of the covariance matrices of sets of prosperous and non-prosperous companies is rejected. Due to the result of this test, it may be appropriate to consider using a quadratic discriminant analysis instead of a linear one. This, however, is more difficult to interpret as linear discriminant analysis and moreover, in SPSS software, which was used for model creating and statistical processing of data, there is no quadratic discriminant analysis implemented. Violation of the assumption of the covariance matrices equality may adversely affect the resulting classification ability of the model. However, as we will see, the small companies' model's classification ability, obtained through a linear discriminant analysis is sufficient. In order to ensure the validity of the conclusions, an assumption of separate-group covariance matrix instead of the within-group covariance matrix was used.

The assumption of independence of explanatory variables was also verified. Given the results of the test of significance of the correlation coefficients among the variables, it can be said that although in 
some cases, the coefficients of correlations are considered to be statistically significant, they are very weak or, at most, weak, with a maximum value of 0.163 .

Using a stepwise discriminant analysis, the final prediction model of financial difficulties of small companies in Slovakia was received. With this model, for each company can be calculated its Z-score as follows:

$Z-$ score $=-0,263 \cdot X 04-5,823 \cdot X 07+3,022 \cdot X 10-0,707 \cdot X 21+0,019 \cdot X 25+4,707$.

$X 27-0,069 \cdot X 28-1,592$

Since this model is created with a constant, the company's belonging to one of the groups of prosperous or non-prosperous companies is determined by comparing its Z-score (Eq. 1) to zero. If the $Z$-score of the company is negative, this company is included in the group of prosperous companies and vice versa, if its Z-score is positive, it will be in the group of non-prosperous ones.

The quality of the prediction model can be assessed by using a canonical correlation of the discriminant function and a test of its statistical significance. The canonical correlation of discriminant function is 0.297 . This correlation is statistically significant, as confirmed by a significance test whose p-value is zero. The obtained discriminant function thus sufficiently distinguishes the two groups of companies.

In the following table (Table 5), the discrimination ability of the variables to distinguish companies in financial difficulties and healthy ones is given. Based on these coefficients, the variables X07 and X27 and X10 can be considered as best discriminators.

Table 5. Standardized Canonical Discriminant Function Coefficients (Source: author's compilation)

\begin{tabular}{|c|c|}
\hline Variable & Function \\
\hline $\mathrm{X} 04$ & -0.304 \\
\hline $\mathrm{X} 07$ & -1.201 \\
\hline $\mathrm{X} 10$ & 0.940 \\
\hline $\mathrm{X} 21$ & -0.099 \\
\hline $\mathrm{X} 25$ & 0.167 \\
\hline $\mathrm{X} 27$ & 1.019 \\
\hline $\mathrm{X} 28$ & -0.064 \\
\hline
\end{tabular}

In the following table (Table 6), the values of the correlation coefficients of each variable and the resulting discriminatory function can be seen. The strongest correlation is between the discriminating function and the variable X10. In addition, this variable is positively correlated with a discriminatory function. Except for X21, all other variables are negatively correlated.

Table 6. Structure Matrix (Source: author's compilation)

\begin{tabular}{|c|c|}
\hline Variable & Function \\
\hline $\mathrm{X} 10$ & 0.802 \\
\hline $\mathrm{X} 04$ & -0.534 \\
\hline $\mathrm{X} 07$ & -0.529 \\
\hline $\mathrm{X} 27$ & -0.501 \\
\hline $\mathrm{X} 28$ & -0.417 \\
\hline $\mathrm{X} 25$ & -0.312 \\
\hline $\mathrm{X} 21$ & 0.154 \\
\hline
\end{tabular}


Finally, the model's classification ability was evaluated using the classification table. As the first part, the percentage of correct classification of companies in the test sample was evaluated. The model correctly classified $73.5 \%$ of all companies. But, what is more important to us is that $93.1 \%$ of companies with financial problems were correctly marked as non-prosperous. Since this model's classification ability may be slightly overestimated by using the original test sample, the percentage of the correct classification of small companies was verified by the training sample, which accounted for $20 \%$ of the original data file. This evaluation constitutes the second part of the classification table (Table 7) below.

Table 7. Classification table (Source: author's compilation)

\begin{tabular}{|c|c|c|c|c|c|}
\hline \multicolumn{3}{|c|}{$\mathbf{Y}$} & \multicolumn{2}{|c|}{$\begin{array}{l}\text { Predicted Group } \\
\text { Membership }\end{array}$} & \multirow[t]{2}{*}{ Total } \\
\hline & & & $\mathbf{0}$ & 1 & \\
\hline \multirow{4}{*}{$\begin{array}{c}\text { Test } \\
\text { sample }\end{array}$} & \multirow{2}{*}{ Count } & 0 & 35486 & 17537 & 53023 \\
\hline & & 1 & 1229 & 16486 & 17715 \\
\hline & \multirow{2}{*}{$\%$} & 0 & 66.93 & 33.1 & 100.0 \\
\hline & & 1 & 6.94 & 93.1 & 100.0 \\
\hline \multirow{4}{*}{$\begin{array}{l}\text { Training } \\
\text { sample }\end{array}$} & \multirow{2}{*}{ Count } & 0 & 8815 & 4232 & 13047 \\
\hline & & 1 & 314 & 4153 & 4467 \\
\hline & \multirow{2}{*}{$\%$} & 0 & 67.56 & 32.4 & 100.0 \\
\hline & & 1 & 7.03 & 93.0 & 100.0 \\
\hline
\end{tabular}

In the training sample, the model correctly classified $93 \%$ of the really non-prosperous companies to be non-prosperous. In view of this, the model can be considered to be a sufficiently correct tool to detect the financial difficulties of small companies in Slovakia.

\section{Conclusions}

This article has introduced a model of predicting the financial difficulties of small companies in the Slovak Republic. This model was created by using a linear discriminant analysis. This method is the most widely used one for predicting a company's bankruptcy. It's also thanks to its simple application and interpretability. The model was created on the basis of real data from the financial statements of Slovak small companies that come from the Amadeus database. The prediction model include a total of 24 financial ratios, from which by using a step method in the final model, 7 variables remained. These variables are the best discriminators when determining a company in financial difficulties. The paper also reported the values of the correlation coefficients between the resulting discriminant function and the individual variables included in it. Based on this, correlations can be determined, and it can be understood which variables have positive and the negative impact on the value of the discriminant function, that determines the inclusion of the company into one of the groups. The classification ability of the model is very good; the model correctly ranked up $93.1 \%$ of nonprosperous companies within the test sample and $93 \%$ of non-prosperous companies in the training sample. Correct classification of the company to a group of companies in financial distress is very important because it demonstrates the impending financial difficulties, or even imminent bankruptcy. For company management, this information, that can be achieved through a predictive model one year in advance, is very important, as the company can then take the necessary measures that would enable them to improve the situation and avert the impending difficulties. In future, there is the possibility of verifying the validity of the model or improving its prediction ability by applying it to the more up-todate data of small companies form the year 2017.

\section{Acknowledgements}

This work was supported by the Slovak Research and Development Agency under Grant number APVV-14-0841: Comprehensive Prediction Model of the Financial Health of Slovak Companies. 


\section{References}

Alaka, H. A., Oyedele, L. O., Owolabi, H. A., Kumar, V., Ajayi, S. O., Akinade, O. O., \& Bilal, M. (2018). Systematic review of bankruptcy prediction models: Towards a framework for tool selection. Expert Systems with Applications, 94, 164-184. doi:10.1016/j.eswa.2017.10.040

Alaminos, D., Castillo, A. D., \& Fernández, M. Á. (2016). A Global Model for Bankruptcy Prediction. Plos One, 11(11). doi:10.1371/journal.pone.0166693

Altman, E. I., Iwanicz-Drozdowska, M., Laitinen, E. K., \& Suvas, A. (2014). Distressed Firm and Bankruptcy Prediction in an International Context: A Review and Empirical Analysis of Altmans Z-Score Model. SSRN Electronic Journal. doi:10.2139/ssrn.2536340

Boritz, J. E., Kennedy, D. B., \& Sun, J. Y. (2007). Predicting Business Failures in Canada*. Accounting Perspectives, 6(2), 141-165. doi:10.1506/g8t2-k05v-1850-52u4

Hebak, P., Hustopecky, J., Jarosova, E., \& Pecakova, I. (2007). Vicerozmerne statisticke metody 1. Praha: Informatorium.

Christidis, A., \& Gregory, A. (2010). Some New Models for Financial Distress Prediction in the UK. SSRN Electronic Journal. doi:10.2139/ssrn.1687166

Khademolqorani, S., Hamadani, A. Z., \& Rafiei, F. M. (2015). A Hybrid Analysis Approach to Improve Financial Distress Forecasting: Empirical Evidence from Iran. Mathematical Problems in Engineering, 2015, 19. doi:10.1155/2015/178197

Kliestik, T., Kocisova, K., \& Misankova, M. (2015). Logit and Probit Model used for Prediction of Financial Health of Company, Procedia Economics and Finance, 23, 850-855. doi:10.1016/S2212-5671(15)00485-2.

Kovacova, M., \& Kliestik, T. (2017). Logit and Probit application for the prediction of bankruptcy in Slovak companies. Equilibrium. Quarterly Journal of Economics and Economic Policy, 12(4), $775-791$. Doi:10.24136/eq.v12i4.40

Kral, P., \& Bartosova, V. (2016). Examining interdependence of MDA bankruptcy models' ability to predict and variables involved. In The economies of Balkan and Eastern Europe countries in the changing world - EBEEC 2016. Conference proceedings, 54-61.

Kral, P., Kanderova, M., Kascakova, A., Nedelova, G., \& Valencakova, V. (2009). Viacrozmerne statisticke metody so zameranim na riesenie problemov ekonomickej praxe. [Accessed 19.03.2017]. Available from Internet:

https://www.researchgate.net/publication/265785993_Viacrozmerne_statisticke_metody_so_zameranim_na_ries enie_problemov_ekonomickej_praxe

Misankova, M., Zvarikova, K., \& Kliestikova, J. (2017). Bankruptcy practice in countries of Visegrad Four. Economics and culture, 14(1), 108-118.

Sandin, A. R., \& Porporato, M. (2008). Corporate bankruptcy prediction models applied to emerging economies. International Journal of Commerce and Management, 17(4), 295-311. doi:10.1108/10569210710844372

Singh, B. P., \& Mishra, A. K. (2016). Re-estimation and comparisons of alternative accounting based bankruptcy prediction models for Indian companies. Financial Innovation, 2(1). doi:10.1186/s40854-016-0026-9

Wang, Y., \& Campbell, M. (2018). Do Bankruptcy Models Really Have Predictive Ability? Evidence using China Publicly Listed Companies. International Management Review, 6(2), 77-82.

Zhang, G., Hu, M. Y., Patuwo, B. E., \& Indro, D. C. (1999). Artificial neural networks in bankruptcy prediction: General framework and cross-validation analysis. European Journal of Operational Research, 116(1), 16-32. doi:10.1016/s0377-2217(98)00051-4

Zvarikova, K., Spuchlakova, E., \& Sopkova, G. (2017). International comparison of the relevant variables in the chosen bankruptcy models used in the risk management. Oeconomia Copernicana, 8(1), 145-157. Doi:10.24136/oc.v8i1.10 